\title{
How Indonesian Students Use the Polya's General Problem Solving Steps
}

\author{
Hari Pratikno \\ Yogyakarta State University, Indonesia \\ pratikno.2017@student.uny.ac.id \\ Endah Retnowati \\ Yogyakarta State University, Indonesia \\ e.retno@uny.ac.id
}

\begin{abstract}
General problem-solving steps consist of understanding the problem, developing a plan, implementing the plan and checking the result. The purpose of this study is to explore how well Indonesia junior secondary school students apply these four steps in solving mathematical problems, especially on plane geometry topics. Using a qualitative approach, with a sample of nine students, of which three students were from the low mathematics achievement category, three from the medium and three from the high category, were given a test and instructed to write the answers to each question step by step. The results were described and categorized into four groups. The first group consisted of students who used all of the four steps. The second and the third were for students who used the first three steps or the first two steps respectively. The fourth group was for those who could only show the first step. The study indicated that for this sample the level of mathematic ability corresponded to how the students applied their problem-solving steps. It was found that students with high ability were included in the first group, while those with moderate ability were in the second group. Low ability students were categorized into group four. Nevertheless, there was one student with high ability who did not to do the checking step and there was one student with low ability who was able to develop a plan.
\end{abstract}

Keywords: Polya, mathematical problem-solving, plane geometry

\section{Introduction}

Problem-solving ability is one of the important objectives of the mathematics subjects. According to NCTM (National Council of Teachers of Mathematics, 2000) problem-solving ability is one of the mathematical abilities needed in mathematics learning. Whereas Arslan and Altun (2007) assert that one of the main objectives of mathematics education is the acquisition of learning skills in solving problems. Davidson (2003) states that research on problem-solving has identified several variables that affect performance in problem-solving, namely knowledge, processes and cognitive strategies, differences in individual abilities, and dispositions and internal factors.

Van Gundy (2005) states that problem-solving is a process of how to accomplish what is desired. In general, the situation on the problem is a situation that has never been found before, or at least a specific solution of past experience is unknown. Conversely, decision making is a selection process where one of two or more solutions might be chosen to achieve the desired goal (Huitt, 1992). Problem-solving cannot begin until there is a representation of 
the problem. Different initial knowledge will produce a different representation of the problem (Robertson, 2001).

Pimta Tayraukham, and Nuangchalerm (2009) in a study of the factors influencing mathematics problem-solving ability of sixth grade students stated that problem-solving is considered as the heart of mathematics learning because the skill is not only the study of the subject content but also emphasizes the development of thinking skills and methods. According to Permendikbud Number 21 (2016), in the subject of mathematics students should be encouraged not to give up when solving problems. Thus, solving problems becomes an important part of the national curriculum. NCTM (2000) also recommends that problem-solving be the focus of teaching mathematics because it includes skills and functions that are important parts of everyday life.

Polya $(1945,1988)$ who is known as 'the father of problem-solving', states that there are four general steps that students must take in solving problems. These four steps are: (1) understanding the problem, namely understanding what data is known and unknown with the problem; (2) preparing a resolution plan, which can find the relationship between known and unknown data to make a resolution plan; (3) implementing a settlement plan, which is implementing what has been planned in order to find a solution according to the completion steps; and (4) re-checking, which is checking the solution obtained, then thinking whether the resolution steps or solutions can be used for other problems.

Figure 1 illustrates the stages of problem-solving in a sequence. The first step is to understand the problem, the second step is to plan, the third step is to carry out the plan, and the last step is looking back.

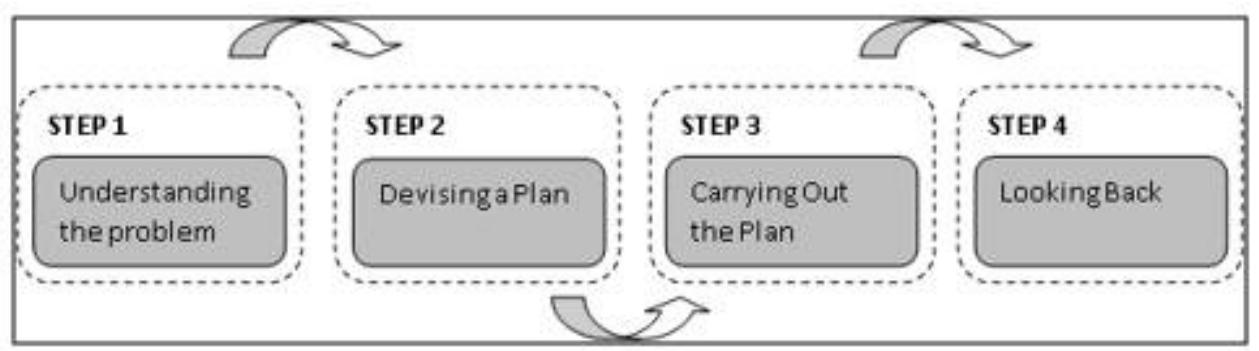

Figure 1. Flowchart steps for Polya's problem-solving.

The sequence illustrates the process and in this study students will be classified according to: group one is for students who are able to understand the problem, to compile and implement the plan, and review the answers; the second group is for students who are able to understand the problem, compile and implement the plan but do not check the answer; the third group is for students who are able to understand the problem and can plan, but cannot implement the plan; and the fourth group is for students who can only understand the problem but cannot make a plan.

Some of the advantages of the following Polya's problem-solving steps are that students: (1) are able to sort out necessary and unnecessary information; (2) can see the main relationship, or make a kind of plan; and (3) can minimize errors because students examine 
each step carefully. Each of the Polya problems solving steps are very important. Sometimes there are students who have brilliant ideas so that they jump over problem-solving steps. This idea might be due to luck alone or insight, but cannot be applied for other types of problems. The worst thing that can occur is if students begin calculations without understanding the problem (Polya, 1988).

The research conducted by Pimta Tayraukham and Nuangchalerm (2009) showed that mathematical problem-solving abilities are influenced by the selection of learning methods that encourage students to enthusiastically learn and have a good attitude towards mathematics learning. The researchers agreed that prior knowledge possessed by students was one of the most important determinants of problem-solving abilities. In addition to the importance of students' prior knowledge, it is suspected that students who do not know the formula for working out problem-solving problems will find it difficult to implement Polya's problem-solving steps.

Geometry is a part of mathematics that is very close to the students' life because almost all visual objects around them are studied in geometry (Baki, Kosa, \& Guven, 2011). Learning geometry topics emphasizes the importance of exploring different representations such as manipulatives, written mathematical formulas, and verbal explanations, which help students build their knowledge concepts and can train critical thinking (Hwang, 2012). It is not surprising then to discover that mathematics which is multidimensional makes use of the multifunctionality of the brain.

When we work on mathematics, in particular, brain activity is spread out across a widely-

distributed network, which include two visual pathways: the ventral and dorsal visual pathways. (Boaler, Chen, Williams, \& Cordero, 2016. p. 325).

Brain research has highlighted the importance of visual thinking to mathematics teaching and learning and re-established the importance of geometry in the school curriculum (Boaler, Chen, Williams, \& Cordero, 2016). Plane geometry is a topic covered in the seventh and eighth grades of Indonesian junior secondary schools in the second semester.

The purpose of this study was to explore how students apply the four Polya steps in solving mathematical problems, especially with plane geometry topics. These four steps indicate the level of problem-solving skills demonstrated by the students. By describing how students use the general steps, teachers may be able to develop instructional strategies that are best suited for them, and hence students can then improve their problem-solving skills.

\section{Methodology}

This research study used a descriptive approach. Subjects in this study were nine students in grade 9 in a private secondary school in Yogyakarta. This study does not aim to generalize the results for wider group of students, but the selection of nine participants was for the purpose of exploring how they could apply the concept of Polya's general problemsolving skills.

At the school, the teacher always uses a written approach to mathematics questions with the students, thus the students are used to completing problem-solving in writing. To 
determine the level of mathematics achievement, their previous performance was used. Table 1 shows the criteria of the mathematics score of each student $(X)$ calculated by the average score of the mathematics school examination $(\bar{X})$, and the standard deviation $(s)$.

Table 1

Criteria for Determining Student Mathematics Achievement

\begin{tabular}{cc}
\hline Interval & Criteria \\
\hline$X \geq \bar{X}+0,5 s$ & High \\
$\bar{X}-0,5 s \leq X \leq \bar{X}+0,5 s$ & Medium \\
$X<\bar{X}-0,5 s$ & Low \\
\hline
\end{tabular}

The ninth grade in the school under study has two classes. Class 9A consisting of 22 students and the 9B classes of 20 students. After the data was calculated, there were 14 students in the high category, 6 students in the medium category, and 22 students in the low category. The selection of nine students from the three different categories was chosen after discussing it with the mathematics teacher.

Based on the description in the introduction, indicators of the problem-solving abilities of the students was formulated according to Polya's steps and can be seen in Table 2 below.

Table 2

Indicators of Problem-solving Ability According to Polya

\begin{tabular}{|c|c|c|}
\hline No. & Problem-Solving Steps & Indicators \\
\hline 1 & Understand the problem & $\begin{array}{l}\text { - Writing what is known correctly. } \\
\text { - Writing what was asked correctly. } \\
\text { - Checking the adequacy of the information. }\end{array}$ \\
\hline 2 & Plan problem-solving & $\begin{array}{l}\text { - Restating the problem for the right } \\
\text { mathematical model. } \\
\text { - Writing the model or formula correctly. }\end{array}$ \\
\hline 3 & Implement a problem-solving plan & $\begin{array}{l}\text { - Performing calculations correctly. } \\
\text { - Writing down answers in a complete, } \\
\text { systematic and correct manner. }\end{array}$ \\
\hline 4 & Looking back & $\begin{array}{l}\text { - Substituting the solution obtained into the } \\
\text { initial formula or use another method. }\end{array}$ \\
\hline
\end{tabular}

The data in this study were obtained from the results of the essay test and the interviews with students were used to clarify their performance on the test. The essay question was chosen, so that the steps of the students in working on the questions are viable. The test was completed within 15 minutes. The questions can be seen in Figure 2. 


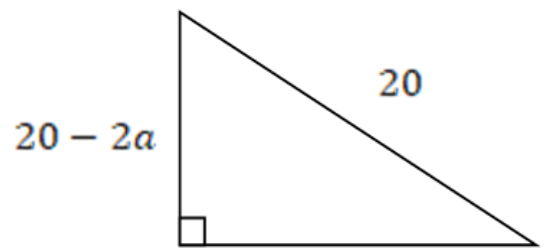

$20-a$

Students are asked to calculate the value of $20+2 a$, then are asked to write: (1) What is known and asked, (2) Write mathematical formulas or models, (3) Steps/ how to calculate it, and (4) Check the answer again by substitution or other.

Figure 2. Problem solving question.

In the case of known right triangles, the lengths of the sides are $(20-2 a) \mathrm{cm},(20-$ a) $\mathrm{cm}$, and $20 \mathrm{~cm}$. Students are asked to determine the value of $20+2 a$. Students' answers are coded according to the indicators found in table 2. Then grouped into categories from group one to group four. Then the data was analyzed and the patterns observed after which it was described. The test results were corrected by researchers and two mathematics teachers as a data triangulation technique. If there were differences in the corrections, it was discussed. The researcher then grouped the data obtained, simplified and reduced the data, then interpreted the findings based on these data.

\section{Results and Discussion}

The results of this study involve description of student's work with problem-solving in geometry. Each student's work was identified according to the application of the Polya's general problem-solving process. The overall results indicated that there were four groups. Table 3 shows the different categories of the problem-solving stages in student mathematical achievement.

Originally at the start of the study the nine students were chosen across the three different categories of mathematical achievement, namely three high category students, three medium category students, and three low category students. The results at the completion showed there were two students who could solve the problems until Polya's fourth step. They were two high-ability mathematics students. Of the four students who could solve problems only until the third step of Polya, one student was from the high mathematics skills and three students from medium mathematics skills. Of the students who could solve problems until the second step of Polya, one student was from the low mathematics ability. Then there were two students who could only reach Polya's first step and who both came from the category of mathematics ability.

Table 3

Student Mathematics Achievement and Category of Problem-solving Steps Were Found in Applying Polya's Steps

\begin{tabular}{lccl}
\hline No. & Respondents & $\begin{array}{c}\text { Student Mathematics } \\
\text { Achievement }\end{array}$ & $\begin{array}{c}\text { Category of Problem } \\
\text { Solving Steps }\end{array}$ \\
\hline 1 & Student 1 (S1) & High & Group 1 (G1) \\
2 & Student 2 (S2) & High & Group 1 (G1) \\
3 & Student 3 (S3) & High & Group 2 (G2) \\
\hline
\end{tabular}




\begin{tabular}{llcl}
\hline No. & Respondents & $\begin{array}{c}\text { Student Mathematics } \\
\text { Achievement }\end{array}$ & $\begin{array}{c}\text { Category of Problem } \\
\text { Solving Steps }\end{array}$ \\
\hline 4 & Student 4 (S4) & Medium & Group 2 (G2) \\
5 & Student 5 (S5) & Medium & Group 2 (G2) \\
6 & Student 6 (S6) & Medium & Group 2 (G2) \\
7 & Student 7 (S7) & Low & Group 3 (G3) \\
8 & Student 8 (S8) & Low & Group 4 (G4) \\
9 & Student 9 (S9) & Low & Group 4 (G4) \\
\hline
\end{tabular}

Table 3 shows that the higher the students' mathematical achievement, the higher the problem-solving ability. Likewise, if students' mathematical achievement was low then the problem-solving abilities tended to be low. Below are some students' answers to each stage of the Polya problem-solving steps.

\section{Students work on 4 steps}

The students' answers in Figure 3, fulfill the four steps of solving Polya's problem of understanding the problem, devising a plan, carrying out the plan, and looking back.

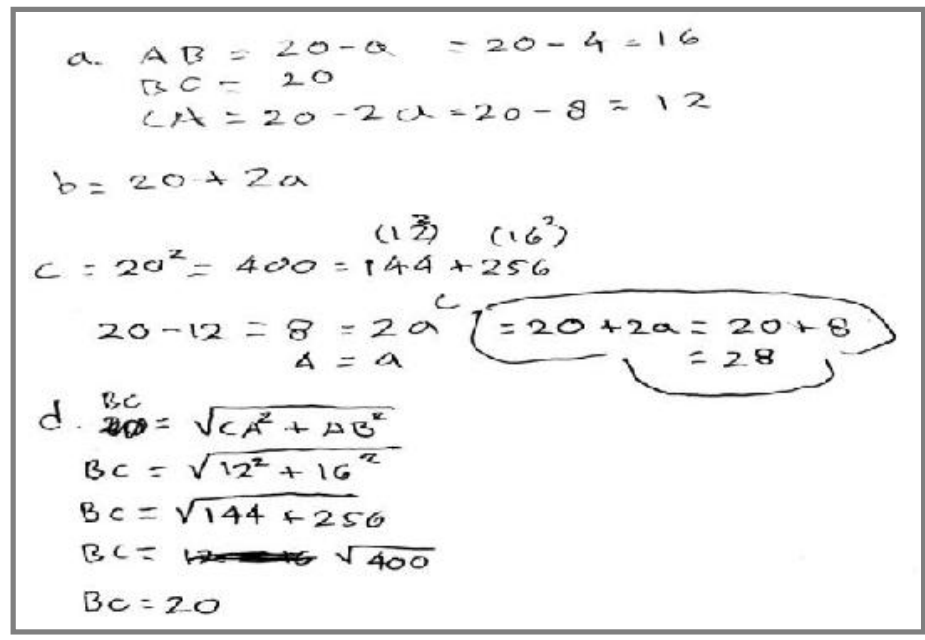

Figure 3. Student answers with Polya's four steps.

What do you think is the difficulty level of the question, is it easy/ medium / difficult?

Bagaimana menurutmu tingkat kesukaran soal, apakah mudah/sedang/sulit?

Sedang medium

Berikan penjelasan/alasan kenapa soal tersebut kamu anggap mudah/sedang/sulit! Give an explanation why do you think the question is easy/medium / difficuit? tidak menemulan cara cepat not find a fast way

Figure 4. A student's explanations about working on problem-solving questions. 
Students who applied the four Polya problem-solving steps demonstrated that: In the first step, writing what was known and what was being asked; Then planned to resolve the problem with the Pythagorean theorem; Then calculated the value of $a$ (Uniquely here students had previously guessed the lengths of the triangular sides with Pythagorean triples.); Then at the end, checked the answer by means of the Pythagorean theorem rules.

Students assumed that the problem is not too difficult, but students still could not work quickly.

\section{Students work on 3 steps}

The students' answers in Figure 5, fulfils the three steps of solving Polya's problem of understanding the problem, devising a plan, and carrying out the plan.

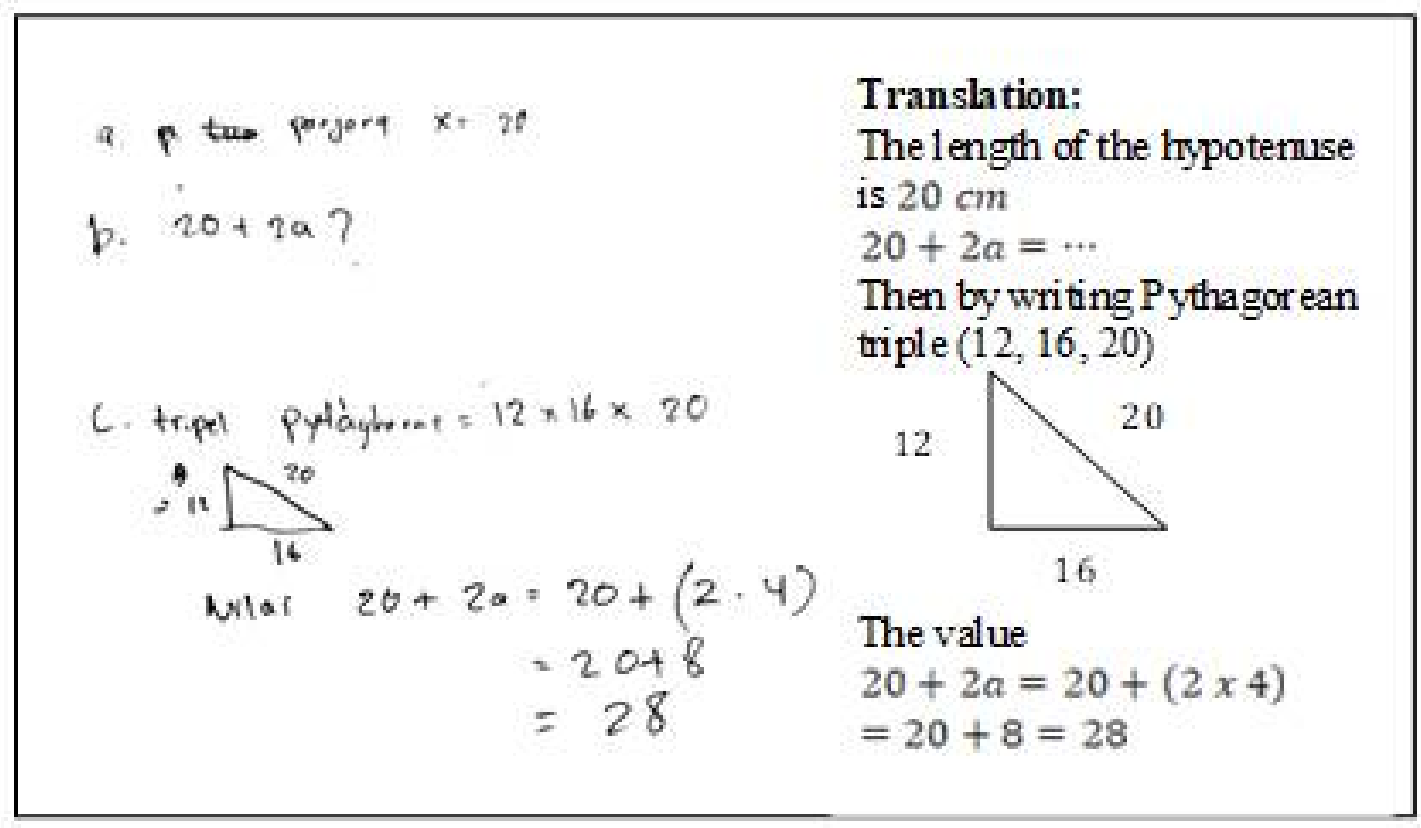

Figure 5. Student answer with Polya's three steps.

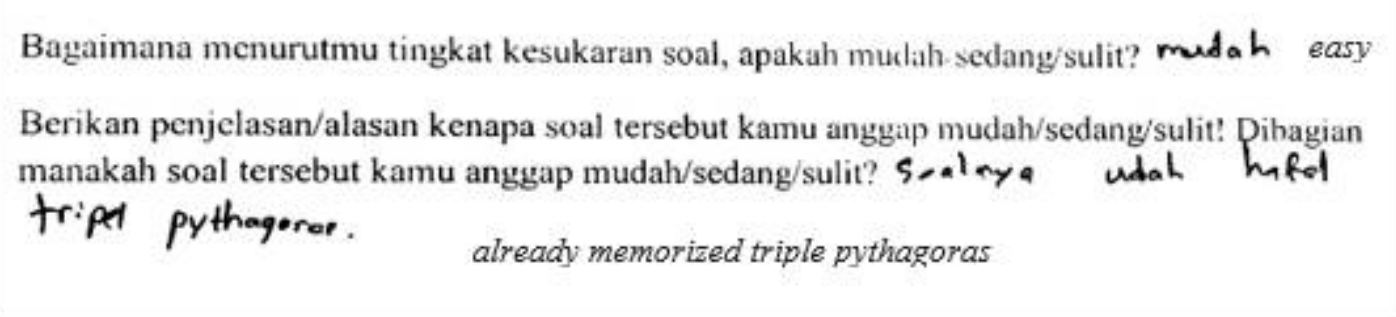

Figure 6. Students' explanations about working on problem-solving questions.

In Figure 5, students completed three steps of the Polya problem-solving process but did not check the answer again. Students consider the question easy because they have memorized Pythagorean triples, but students are confused about how to check the truth of the answer. 


\section{Students work on two steps}

The students' answers in Figure 7, fulfils the four steps of solving Polya's problem of understanding the problem and devising a plan.

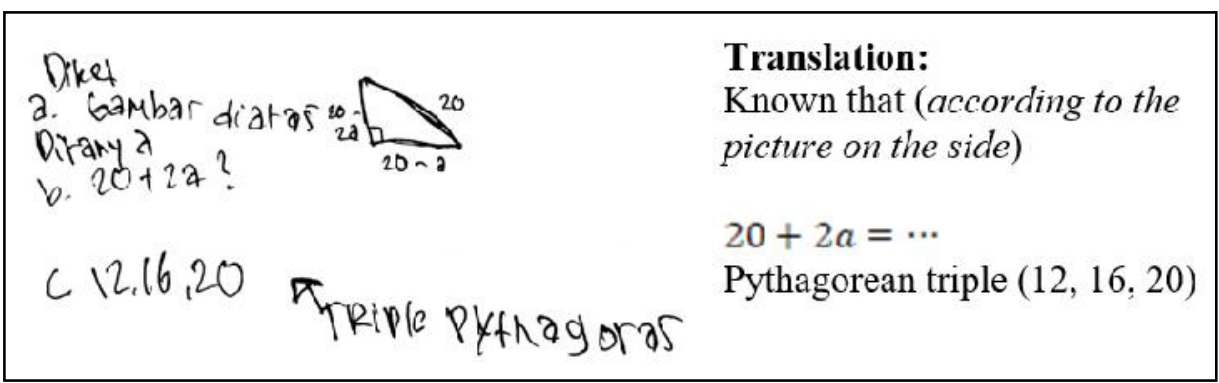

Figure 7. Student answers with two steps Polya.

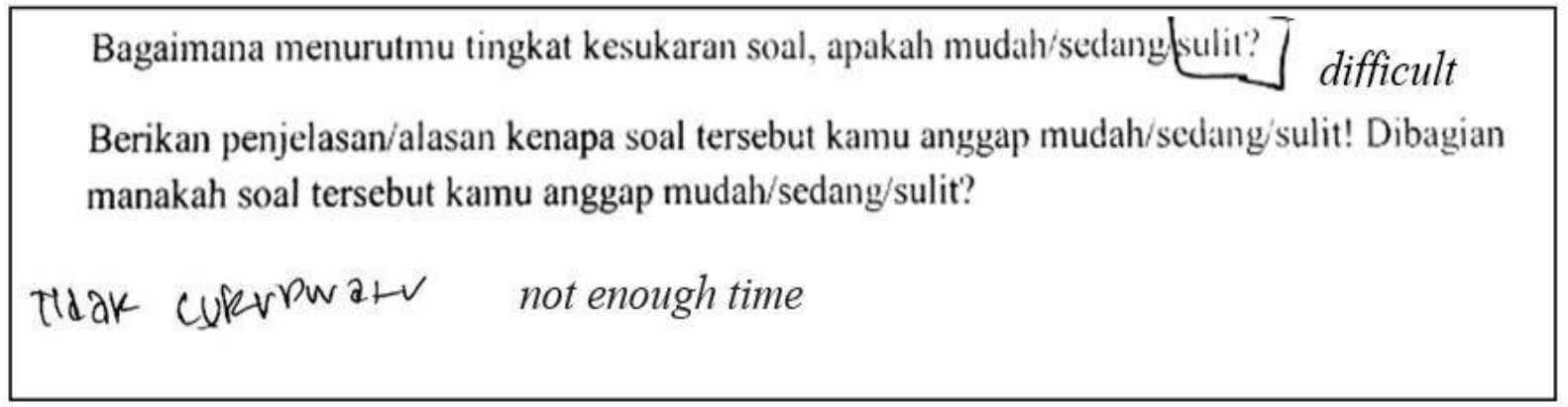

Figure 8. Students' explanations about working on problem-solving questions.

In Figure 7, the student stops at the second Polya problem-solving step. The student could only understand the problem and plan what would be done. The student's plan is seen when the student writes the Pythagorean triple, meaning that the student was able to plan what would be done and the student could determine the right Pythagorean triple, but the student would not determine the value of ' $a$ '. According to the student in figure 8 , this problem is moderate but $\mathrm{s} / \mathrm{he}$ felt that there was not enough time to work on it.

\section{Students work on a single step}

The student's answer is showm in Figure 9, and fulfils only one Polya problemsolving step, which is understanding the problem.

$$
\begin{aligned}
& T_{\Delta}=20-2 q \\
& A_{\Delta}=20-q \\
& P_{\Delta}=20 \\
& N_{i}=20+2 q
\end{aligned}
$$

Figure 9. Student answers with one step Polya. 


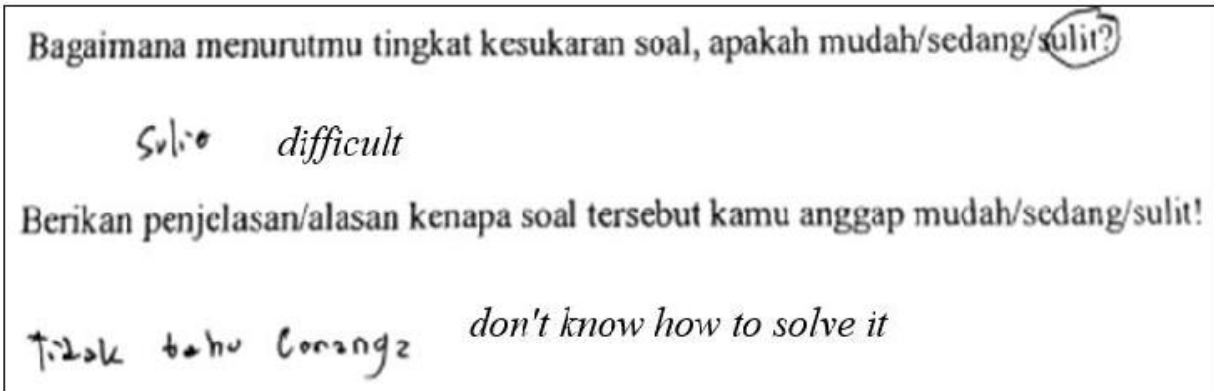

Figure 10. Students' explanations about working on problem-solving questions.

In Figure 9, a new student only wrote what is known and what is being asked. This means that the student understands the problem, but has not been able to plan the problemsolving process. According to the student, the problem is difficult and the student did not understand how to do it.

The stages of solving mathematical problems are very important for the teacher to study so that the teacher can develop the right pedagogical that can improve the students' problem-solving skills. Based on the results of the interviews with students, the data implied that the general problem-solving steps needed to be studied by students because there were students who had difficulty using them. Polya's problem-solving steps are very important to assist students' coherent thinking patterns.

\section{Conclusion}

Due to the sample limitations of this study, the findings can only apply to the students in the sample and cannot be regarded as representing a wider group of Indonesia students. However, the finding can be of interest to teachers and educators in making comparisons with their own situation.

It can be concluded that the sample students with high mathematical achievement could use the four steps correctly, and the lower the the student's mathematical achievement the less steps they could accomplish. Although this study may be limited in terms of the number of the participants, the exploration reveals evidence that general problem-solving skills might not be something that is naturally possessed by students. To some extent, the teacher should direct the students to study the steps explicitely. It may be likely that the results of this study may be transferred into other mathematics topics, however further investigation is suggested.

\section{References}

Arslan, C., \& Altun, M. (2007). Learning to solve non-routine mathematical problems. Elementary Education Online, 6(1), 50-61.

Baki, A., Kosa, T., \& Guven, B. (2011). A comparative study of the effects of using dynamic geometry software and physical manipulatives on the spatial visualisation skills of preservice mathematics teachers. British Journal of Educational Technology, 42(2), 291310. 
Boaler, J., Chen, L., Williams, C., \& Cordero, M. (2016). Seeing as Understanding: The Importance of Visual Mathematics for our Brain and Learning. Journal Applied Computational Mathematics, 5(5), 325-31. doi: 10.4172/2168-9679.1000325

Davidson, J. E. \& Sternberg, R. J. (2003). The psychology of problem solving. London, UK: Cambridge University Press.

Huitt, W. (1992). Problem solving and decision making: Consideration of individual differences using the myers-briggs type indicator. Journal of Psychological Type, 24, 3344.

Hwang, Wu-Yuin \& Hu, Shin-Shin. (2013). Analysis of peer learning behaviors using multiple representations in virtual reality and their impacts on geometry problem solving. Computers and Education, 62, 308-319.

Jonassen, D. H. (2011). Learning to solve problem: an instructional design guided. San Fransisco, CA: Pfeiffer.

National Council of Teachers of Mathematics (2000). Principles and standards for school mathematics. Reston, VA: NCTM

Permendikbud. (2016). Salinan lampiran peraturan menteri pendidikan dan kebudayaan nomor 21 tahun 2016 tentang standar isi pendidikan dasar dan menengah.

Pimta, S,.Tayraukham, S., \& Nuangchalerm, P. (2009). Factors influencing mathematics problem solving ability of sixth grade students. Journal of social sciences, 5(4), 381-385.

Polya, G. (1988). How to solve it, a new aspect of mathematical method. New Jersey: Princeton University Press.

Pólya, G. (1945). How to Solve It. Princeton University Press

Robertson, S. I. (2001). Problem solving. East Sussex: Psychology Press.

VanGundy, A. B. (2005). 101 Activities for teaching creativity and problem solving. USA: Tlf eBook. 